\title{
Topical action of Buriti oil (Mauritia flexuosa L.) in myositis induced in rats ${ }^{1}$
}

Marília Ursulino Barbosa', Marcello de Alencar Silva", Esmeralda Maria Lustosa Barros"', Margarida Ursulino Barbosalv, Rayssilane Cardoso de Sousav, Mateus Aguiar da Costa Lopes ${ }^{\mathrm{V}}$, Nayana Pinheiro Machado de Freitas Coelho ${ }^{\mathrm{VII}}$

'MD, Faculdade Integral Diferencial (FACID| DeVry), Teresina-PI, Brazil. Acquisition of data, manuscript writing.

"PhD, Biotechnology, Rede Nordeste de Biotecnologia (RENORBIO), Universidade Federal do Piauí (UFPI), and Full Professor, FACID| DeVry, Teresina-PI, Brazil. Statistical analysis.

"'Laboratory technician, UFPI, Teresina-PI, Brazil. Acquisition of data.

IVPhysiotherapist, Intensive Therapy, Instituto Camilo Filho (ICF), Teresina-PI, Brazil. Acquisition of data.

${ }^{v}$ Fellow PhD degree, Postgraduate Program in Biotechnology in Health, RENORBIO, UFPI, Teresina-PI, Brazil. Manuscript preparation.

V'Graduate student, FACID | DeVry, Teresina-PI, Brazil. Manuscript preparation.

VIIPhD, Biomedical Engineering, Universidade do Vale do Parnaíba (UNIVAP), Sao Jose dos Campos-SP, Full Professor, UEPI, Teresina-PI, Brazil. Analysis and interpretation of data, final approval.

\section{Abstract}

Purpose: To analyze the topical effects of Buriti oil (Mauritia flexuosa L.) in induced myositis in rats.

Methods: Thirty six male rats divided into three groups: Control group (C), induced myositis group (MI) and induced myositis group reated with Mauritia flexuosa L. (MT). After inducing myositis with $1 \%$ acetic acid, was topically applied $0.5 \mathrm{ml}$ of Mauritia flexuosa L.extract on the posterior region of the right gastrocnemius muscle in animals belonging to group MT, for 7 and 14 days.

Results: The neutrophil number there was statistically significant difference, after 7 and 14 days, between groups $C$ and $\mathrm{MI}(p<0.001)(p<0.01)$. The group MT there was a significant difference in relation to $\mathrm{MI}$ group in both experimental times with $(\mathrm{p}<0.001)$. The number of fibroblasts in the 14 days showed that when comparing the groups $M$ and $M T$ the differences were also significant $(p<0.001)$. As for the $D L L$, in 7 days, there was a significant difference between group $C$ and $M I$ group $(p<0.001)$. When considering the MT group, there was a significant difference in relation to the MI group $(p<0.001)$.

Conclusion: The extract of Mauritia flexuosa L. leaves lessened acute and chronic inflammation, increased fibroblast proliferation and reduced macroscopically edema.

Key words: Myositis. Plants, Medicinal. Rats.. 


\section{- Introduction}

Diseases that compromise the structure or the primary function of the muscle may result from various inherited disorders (congenital myopathies, muscular dystrophies, myotomies and channelopathies, primary metabolic myopathies, mitochondrial myopathies) and acquired (inflammatory, toxic and drug induced myopathies, metabolic secondary, endocrine and infectious diseases ${ }^{1}$.

Myositis is an inflammatory myopathy and comprises a heterogeneous group of chronic autoimmune systemic myopathies associated with high morbidity and functional disability. Each one presents different epidemiological, histological, immunohistochemical, pathological, clinical and evolutionary characteristics ${ }^{2}$.

This group of diseases is characterized by a non-suppurative inflammatory process in the skeletal musculature and is clinically manifested by bilateral and symmetrical muscular weakness. Proximal and symmetrical muscle weakness is its main symptom. Other symptoms observed include fatigue, asthenia, myalgias, fever, weight loss, arthralgia and arthritis of small and medium joints ${ }^{3}$.

The inflammatory process represents a critical phase of tissue repair, triggered in response to a particular etiological agent. As a defense mechanism, it encompasses a broad contingent of chemical mediators capable of acting at the site of the aggression or systemically ${ }^{4,5}$.

The definitive diagnostic procedure for idiopathic inflammatory myopathies (MII) is through muscle biopsy revealing lymphocytic infiltrates, necrosis and regeneration of muscle fibers. Most patients present a favorable response to treatment with glucocorticoids and immunosuppressants; intravenous immunoglobulins are also used in those in severe condition $^{6,7}$.
Medications, almost all of them, present a single active principle responsible for its pharmacological effect and with a high acquisition cost. The plant extracts are constituted by mixtures of active substances, partially active and inactive that act in different pharmacological targets. The phytotherapeutic activities of buriti oil and its popular use are known to reduce inflammatory processes due to rheumatological changes. The efficacy of these extracts is the result of their use, for many years, by different ethnic groups ${ }^{8}$.

The chemical and pharmacological composition of buriti oil rich in carotenoids, fatty acids and tocopherol suggests a good perspective in the use of this product as a therapeutic and cosmetic alternative ${ }^{9,10}$.

Several drugs obtained from medicinal plants are used with anti-inflammatory and healing ${ }^{8-10}$. However, some natural extracts have the use based only on popular knowledge. The therapeutic potential of buriti oil opens the prospect to make it promising in front of inflammatory interventions in the skeletal muscle.

The objective of this study was to analyze the topical effects of buriti oil (Mauritia flexuosa L.) on myositis induced in rats and, as a specific objective, to measure edema macroscopically in myositis induced in rats and quantitatively evaluate the inflammatory cells and fibroblasts in induced myositis in rats.

\section{Methods}

The study was approved by the Animal Ethics Committee - AEC of FACID/DeVry with the protocol №. 057/14, according to the Arouca Federal Law No. 11.974/2008 - Animal Experimentation.

\section{Experimental groups}

The research was performed at the Laboratory of Physiology of a Private Institution 
in the city of Teresina - Piauí. 36 male rats (Rattus norvegicus albinus) of the Wistar lineage, with average body weight between 250-300g, were randomly allocated to three groups $(n=$ 12 animals, each), according to the adopted therapy, and each group was subdivided into Two subgroups ( $n=6$ animals, each) according to the observation period / euthanasia of 7 and 14 days. The experimental groups were: Control Group (C), Myositis induced (MI) and Myositis induced and treated with the oil extraction of M. flexuosa L. (MT).

\section{Induction of experimental injury}

The animals were weighed and then independently anesthetized with $10 \%$ ketamine hydrochloride $(0.1 \mathrm{ml} / 100 \mathrm{~g}$; provided by Syntec do Brasil Ltda, São Paulo, Brasil), associated with the same dose of $2 \%$ xylazine hydrochloride $(0.1 \mathrm{ml} / 100 \mathrm{~g}$; provided by Syntec do Brasil Ltda, São Paulo, Brasil), intramuscularly.

To induce myositis, after manual epication of the dorsal region of the right hind limb of the animal, followed by asepsis with polyvinyliodopyrrolidone (PVPI), $0.2 \mathrm{ml}$ of $1 \%$ acetic acid with hypodermic needle and insulin syringe were injected into the right gastrocnemius muscle ${ }^{11}$.

\section{Preparation of the Mauritia flexuosa oil extract}

Buriti fruits were washed in running water, submerged in sodium hypochlorite solution at $50 \mathrm{mg} / \mathrm{kg}$ for five minutes, and after that period, the fruits were manually pulped with a stainless steel knife and cut into slices of $0.3 \mathrm{~cm}$ thickness, $1.6 \mathrm{~cm}$ width $2.8 \mathrm{~cm}$ length. The buriti pulp was ground in a multiprocessor for one minute, the pulp samples being subjected to the oil extraction by cooking in natural water; then the supernatant was filtered to acquire the buriti oil, which was kept in the refrigerator throughout the development.

\section{Experimental treatment}

The myositis was induced only once. The observation period of the groups was 7 and 14 days for the acute and chronic phases, respectively. Animals in group $\mathrm{C}$ received no pharmacological intervention. In the $\mathrm{MI}$ group, induction of myositis with $1 \%$ acetic acid was performed. In the MT group, myositis induction was performed with $1 \%$ acetic acid and later the animals were treated with the oil extraction of $M$. flexuosa $\mathrm{L}$.

The myositis of the MT group was treated with topical administration without manual rubbing of $0.5 \mathrm{ml}$ of buriti oil daily over the back region of the right gastrocnemius every day immediately after the induction of myositis (Figure 1).

The animals were euthanized with an overdose $(60 \mathrm{mg} / \mathrm{kg}$ ) of anesthetic (Thiopental Sodium) intraperitoneally, in order to obtain the sample for histological analysis.

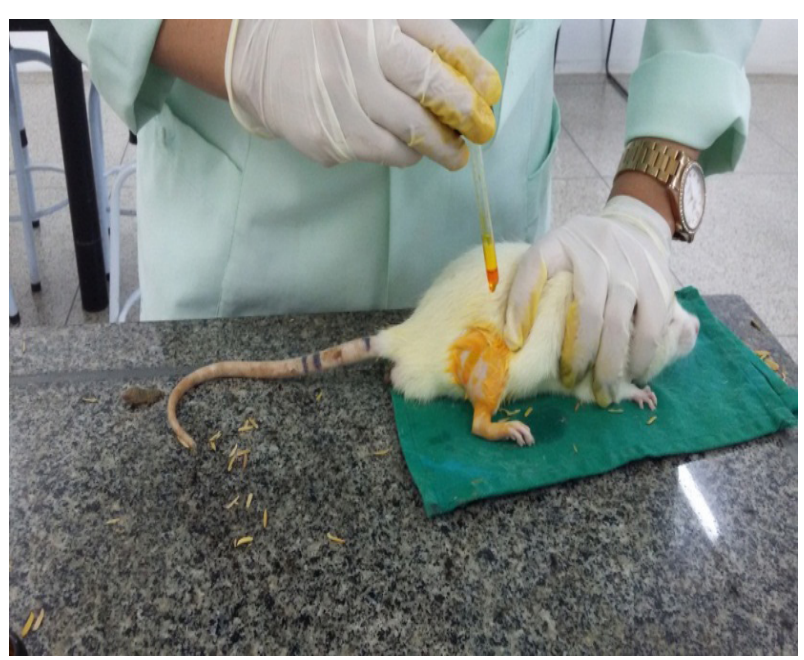

Figure 1 - Topical treatment of the oil extraction of Mauritia flexuosa $L$. in the right gastrocnemius of the rat with induced myositis. 


\section{Measurement of the posterior-lateral} diameter of the posterior limb

The measurement of the right posterior limb length was performed with digital caliper, taking as limits the tibio-femoral and tibiocalcaneal joints, whose half of this length served as a standard for the posterior-lateral diameter (DLL) measurement site in the hind limbs of the rats $^{12}$. The evaluation of the edema evolution was made by comparing the DLL before the acetic acid injection in the right gastrocnemius muscle, as well as by measuring the DLL on the days following the experimental procedure throughout the observation periods on all days of the experiment under anesthesia ${ }^{12}$ (Figure 2).

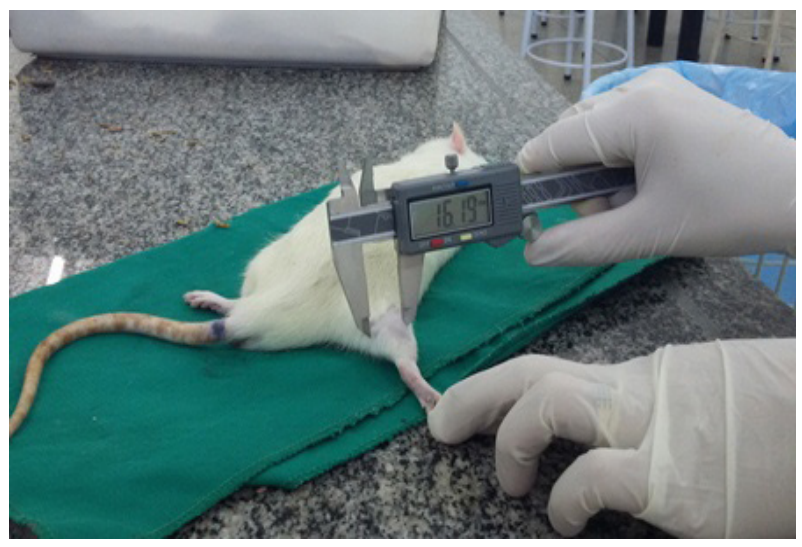

Figure 2 - Measurement of the lateral-lateral diameter of the hind limbs of the rats with the digital caliper.

\section{Histopathological Analysis}

The right gastrocnemius muscle was fixed in $10 \%$ formaldehyde and then subjected to routine histological procedures. Histological sections with $5 \mu \mathrm{m}$ thickness were stained with hematoxylin-eosin (HE).

After the acquisition of the images of the blades stained with $H \& E$, the counting of inflammatory cells was performed under x40 magnification in three fields of each slide, delimited with a linear grid that subdivided the area into $0.4 \mathrm{~mm}^{2}$.

The slides were then analyzed by optical microscopy through quantitative analysis, for which ImageJ $^{\bullet}$ software was used to count inflammatory cells and fibroblasts

The analyzed region was randomly chosen and its upper and left lateral border drawn in blue and the lower and right lateral border in red. The nucleus present were individually marked by the tool of manual counting of the program, being considered the cells that were inside the delimited area and that touched the lines traced in the blue color. The cells that touched the red lines were not counted.

\section{Statistical analysis}

The statistic was obtained with the help of the One way Anova post hoc test Turkey test, through the GraphPad Prism Program, v. 5.0. Values were considered significant when $p<0.05$.

\section{- Results}

In the experimental period of 7 days, the presence of inflammation was observed in rats of the myositis induced group (MI), since the amount of neutrophils was significantly higher $(p<0.001)$ compared to the control group (C). These results were also observed in the experimental time of 14 days $(p<0.01)$. In the Myositis group treated with $M$. flexuosa L. (MT), the amount of neutrophils showed a significant reduction in relation to the $\mathrm{MI}$ group $(p<0.001)$ in both experimental times, evidencing that the oil extract of $M$. flexuosa $\mathrm{L}$. reduced the process In this study (Figure 3). 


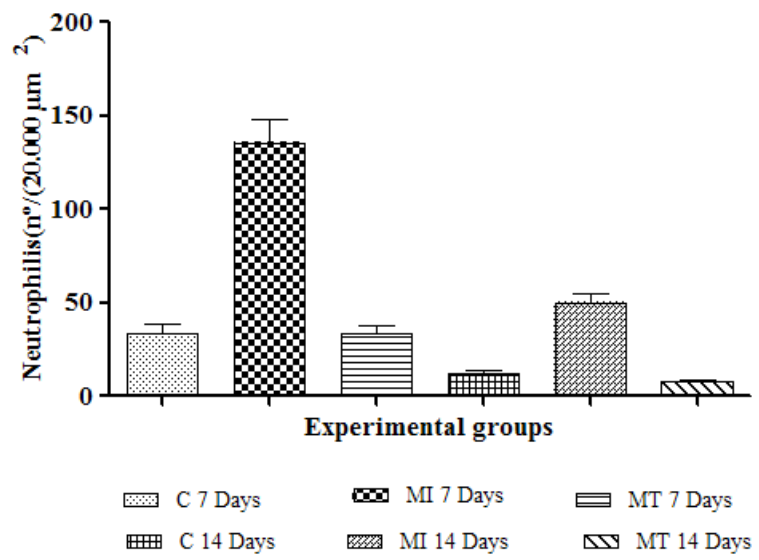

Figure 3 - Number of neutrophils $\left(20.000 \mu \mathrm{m}^{2}\right)$ found in different groups and experimental times treated with Mauritia flexuosa L. Control group for 7 days (C 7 days), Induced myositis for 7 days (MI 7 days), Induced myositis group treated with oily extraction of Mauritia flexuosa L. for 7 days (MT 7 Days), Control group for 14 days (C 14 days), Group myositis induced for 14 days (MI 14 days), induced myositis group treated with oily extraction of Mauritia flexuosa L. for 14 days (MT 14 days).

In the experimental period of 7 days $(p<0.05)$, as well as at fourteen days $(p<0.001)$, in relation to the number of fibroblasts, there was a statistically significant difference between the MI and MT groups, which suggests the resolution of muscle injury (tissue repair effect in the induced lesion) and proliferation of fibroblasts in the time indicated as direct action of buriti oil. Similarly, when groups C 7 days and MT 7 days, C 14 days and MT 14 days were related, a significant difference was observed with $p<0.01$ and $p<0.001$ (Figure 4).

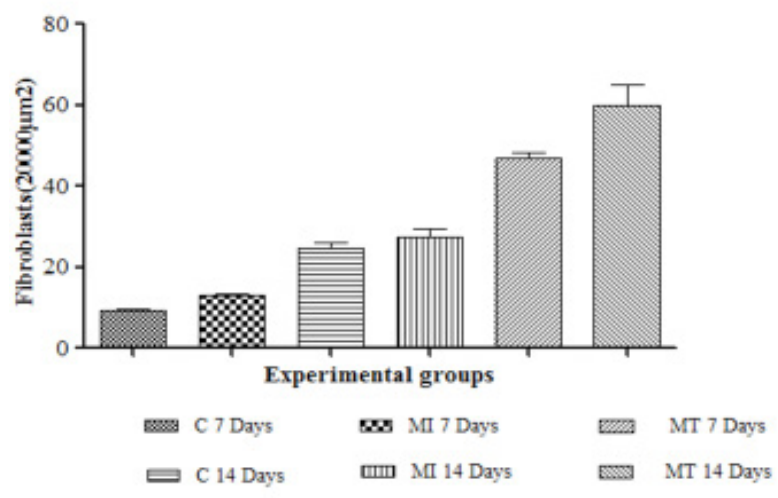

Figure 4 - Number of fibroblasts $\left(20.000 \mu \mathrm{m}^{2}\right)$ found in different groups and experimental times treated with Mauritia flexuosa L. Control group for 7 days (C 7 Days), induced myositis group for 7 days (MI 7 Days), Induced myositis group treated with Mauritia flexuosa L. oil extraction for 7 days (MT 7 Days), Control group for 14 days (C 14 days), Induced myositis group for 14 days (MI 14 days), Induced myositis group treated with oily extraction of Mauritia flexuosa L. for 14 days (MT 14 days).

As for the analysis of the measurement of the lateral-lateral diameter (DLL) performed on the posterior limb of the rats in the experimental time of seven days, it was observed that when the $C$ group was compared with the Ml group, the results were significant $(p<0.001)$, evidencing that myositis was induced by $1 \%$ and generated edema. In the MT group there was a significant difference in relation to the $\mathrm{MI}$ group $(\mathrm{p}<0.001)$, confirming the macroscopic reduction of edema in myositis induced in rats after topical treatment with $M$. flexuosa $\mathrm{L}$. In the 14 days experimental time, there was no significant difference between the groups (Figure 5). 


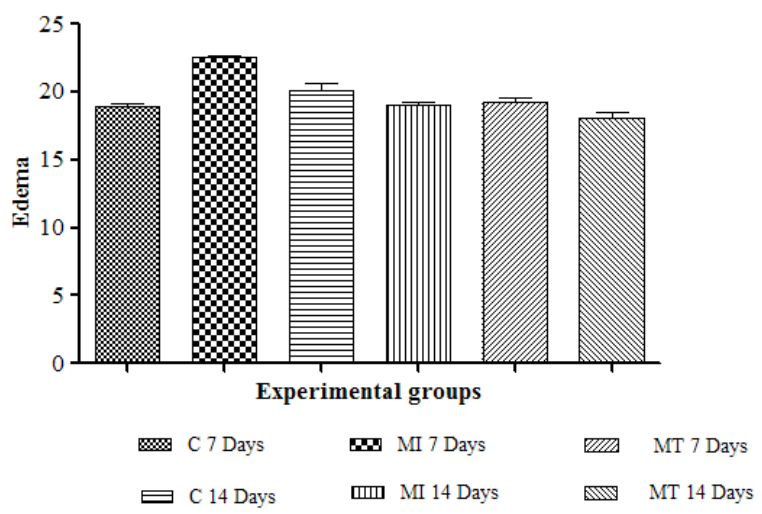

Figure 5 - Mean of the lateral-lateral diameter (DLL) of the right posterior limb of rats found in different groups and experimental times treated with Mauritia flexuosa L. Control group for 7 days (C 7 Days), Induced myositis group (MI 7 Days), Induced myositis group treated with Mauritia flexuosa oil extraction for 7 days (MT 7 Days), Control group for 14 days (14 days), Myositis group induced for 14 days (MI 14 days), Induced myositis group treated with oily extraction of Mauritia flexuosa for 14 days (MT 14 days).

\section{- Discussion}

In this study, the muscle inflammatory process (myositis) was induced by $1 \%$ acetic acid. This acid is one of the substances most used in experimental studies for induction of pain and consequent analysis of the inflammatory process, being an important inducer of inflammation. Acetic acid has been used in studies to induce inflammation of the posterior limbs of rats, including the testing of various substances such as medicinal plants ${ }^{13-15}$.

According to Brito et al. ${ }^{16}$, in studies with the objective of evaluating the effect of acetic acid as an experimental model for the induction of myositis in the hind limb of rats, it was concluded that in both acetic acid concentrations evaluated (1\%, 5\% and 10\%), inflammatory response was similar. Considering these conclusions, the concentration of $1 \%$ of acetic acid was considered the best for the induction of inflammation in the lower limbs of rats because it was the lowest concentration among those studied, enough to cause inflammation.

In the acute inflammatory process a series of interrelated events occur, such as increased blood flow and vascular permeability in the affected region, edema, localized pain, migration and accumulation of inflammatory leukocytes from the blood vessels into the tissue, formation of granulation tissue and tissue repair. Neutrophils are the most abundant leukocytes in the body, accounting for between $60 \%$ and $70 \%$ of the total blood leukocytes ${ }^{17,18}$.

In general, the first cells to reach the injured tissue are neutrophils, which participate in the inflammatory process with phagocytosis and destruction of microorganisms through the production of reactive species of oxygen, nitrogen and degranulation ${ }^{19}$. Thus, the higher neutrophil infiltration in the groups submitted to $1 \%$ acetic acid injection suggests the confirmation of myositis induction to which the animals were submitted (Figure 3 ).

Batista et al. ${ }^{20}$ evaluated the in vitro and healing antibacterial activity of buriti oil (M. flexuosa) on wounds performed in rats (Rattus norvegicus albinus) and concluded that $M$. flexuosa fruit oil showed efficacy in the cicatricial process of cutaneous wounds in wistar rats, since it promoted a greater percentage of contraction of the edges of the wound and was statistically significant in the counting of fibroblasts and collagen fibers in the group treated with buriti oil in relation to the control group, besides antibacterial activity in vitro in both gram positive bacteria and in gram negative.

In this study, the anti-inflammatory activity of buriti oil was evidenced by the reduction of the number of inflammatory cells (neutrophils) at seven and fourteen days after topical treatment with buriti oil. According to 
Santos et $a .^{21}$ and Silva and Pighinelli22, in this oil are present substances such as carotenoids and vitamin $\mathrm{E}$, capable of promoting beneficial effect in the process of tissue repair. The high concentrations of fatty acids present in buriti oil have important role for the formation, deposition of collagen fibers and cellular proliferation, being important for tissue regeneration - results also observed in this research (Figure 4).

The antidematogenic activity of buriti oil was evidenced by reduction of DLL edema of the posterior limb of the rats and such effect observed up to seven days after topical administration of buriti oil. In the experimental model of acute inflammation studied, acetic acid induced inflammation by the formation of edema, inflammatory infiltrate and necrosis ${ }^{16}$. It is considered that any substance that causes inhibition or reduction of the effects of acetic acid is considered as an anti-inflammatory agent $^{16,23-25}$ (Figure 5).

Romero et al. $^{26}$ in their study on carotenoids and flavonoids in pulps and oils of buriti ( $M$. flexuosa L.) concluded that buriti pulps and oils presented as a good source of carotenoids, a potent antioxidant with protective action against cardiovascular diseases.

\section{Conclusions}

Buriti oil (M. flexuosa $\mathrm{L}$ ) had a positive influence on tissue regeneration in rats by promoting a decrease in inflammatory cells (neutrophils) and proliferation of fibroblasts in tissues, as well as reducing edema induced by acetic acid, showing that the active constituents present In the oil of this species showed antiinflammatory activity and that they acted in the fast and late phase of the inflammation. This study suggests that buriti oil presents potential application for therapeutic purposes and should therefore serve as a basis for future research with preclinical studies.

\section{References}

1. McDonald CM. Clinical approach to the diagnostic evaluation of hereditary and acquired neuromuscular diseases. Phys Med Rehabil Clin N Am. 2012;23(3):495563. doi: 10.1016/j.pmr.2012.06.011.

2. Shinjo SK, De Souza FHC, De Moraes JCB. Dermatomiosite e polimiosite: da imunopatologia à imunoterapia (imunobiológicos). Rev Bras Reumatol. 2013;53(1):105-10. doi: 10.1590/S048250042013000100010.

3. Zeigelboim BS, Klagenberg KF, Malucelli DAB, Liberalesso PBN, Paulin F. Achados otoneurológicos em um caso de miopatia inflamatória. Revista CEFAC. 2012;14(1):1-5. doi: 10.1590/S1516-18462010005000054.

4. Rosa Neto NS, Goldenstein-Schainberg C. Dermatomiosite juvenil: revisão e atualização em patogênese e tratamento. Rev Bras Reumatol. 2010;50(3):299-312. doi: $10.1590 /$ S0482-50042010000300010.

5. Chamusca FV, Reis SRA, Lemaire D, Medrado AP. Mediadores do efeito sistêmico do processo inflamatório e terapias fotobiomoduladoras: uma revisão de literatura. Rev Ciênc Méd Biol. 2012;11(1):70-8.

6. Catoggio LJ, Soriano ER, Rosa JE. Tratamiento y prognóstico. Reumatol Clín. 2014;5(1):359. doi: 10.1016/j.reuma.2009.07.004.

7. Nieves AIT, Holguera RM, Sánchez-Atrio $\mathrm{Al}$, Cruz HM. Miopatías inflamatorias idiopáticas. Medicine. 2013;11(33):2040-7. doi: 10.1016/S0304-5412(13)70575-4.

8. Ferreira VF, Pinto AC. A fitoterapia no mundo atual. Química Nova. 2010;33(9):1829. doi: 10.1590/S0100-40422010000900001.

9. Rosso VV, Mercadante AZ. Identification and quantification of carotenoids, by HPLC-PDAMS/MS, from Amazonian fruits. J Agric Food Chem. 2007;55(13):5062-72. doi: 10.1021/ jf0705421.

10.Speranza P, Falcão AO, Macedo JA, Silva LHM, Rodirgues AMC, Macedo GA. Amazonian Buriti oil: chemical characterization and antioxidant potential. Grasas Aceites. 2016;67(2):1-9. doi: 10.3989/gya.0622152.

11.Carvalho AFM, Sousa PFB, Feitosa MCP, Coelho NPMF, Barros EML, Feitosa VC, Arisawa EAL. The low-level laser on acute myositis in rats. Acta Cir Bras. 
2015;30(12):806-11. doi: 10.1590/S0102865020150120000003.

12.Brito MVH, Figueiredo RC, Tavares MLC, Silveira TS, Cantanhêde G. Efeito dos óleos de andiroba e copaíba na miosite induzida em ratos. Rev Para Med. 2006;20(2):17-24.

13.Sheu MJ, Chou PY, Cheng $\mathrm{HC}$, Wu CH, Huang GJ, Wang BS, Chen JS, Chien YC, Huang MH. Analgesic and anti-inflammatory activities of a water extract of Trachelospermum jasminoides (Apocynaceae). J Ethnopharmacol. 2009;126(2):332-8. doi: 10.1016/j.jep.2009.08.019.

14.IseriSO, Ersoy Y, Ercan F, Yuksel M, Atukeren P, Gumustas K, Alican I. The effect of sildenafil, a phosphodiesterase 5 inhibitor, on acetic acid induced colonic inflammation in the rat. J Gastroenterol Hepatol. 2009;24(6):1142-8. doi: 10.1111/j.1440-1746.2009.05797.

15.Kumar T, Jain V. Antinociceptive and antiinflammatory activities of Bridelia retusa methanolic fruit extract in experimental animals. Sci World J. 2014;2014:890151. doi: 10.1155/2014/890151.

16. Brito MVH, Borges RGL, Góes HFO, Silveira EL. Experimental model to myositis induction in mice microscopic evaluation. Rev Para Med. 2012;26(1):1-4.

17.Ricciotti E, FitzGerald GA. Prostaglandins and inflammation. Arterioscler Thromb Vasc Biol. 2011;31(5):986-1000. doi: 10.1161/ ATVBAHA.110.207449.

18.Koh TJ, DiPietro LA. Inflammation and wound healing: the role of the macrophage. Expert Rev Mol Med. 2011;13:e23:1-14. doi: $10.1017 /$ S1462399411001943.

19.van den Berg JM, Kuijpers TW. Educational paper: defects in number and function of neutrophilic granulocytes causing primary imunodeficiency. Eur J Pediatr. 2011;170:1369-76. doi: 10.1007/s00431-
011-1584-5.

20.Batista JS, Olinda RG, Medeiros VB, Rodrigues CMF, Oliveira AF, Paiva ES, Freitas CIA, Medeiros AC. Atividade antibacteriana e cicatrizante do óleo de buriti Mauritia flexuosa L. Cienc Rural. 2012;42(1):136-41. doi: 10.1590/S0103-84782012000100022.

21.Santos JS, Vieira ABD, Kamada I. A Rosa Mosqueta no tratamento de feridas abertas: uma revisão. Rev Bras Enferm. 2009;62(3):457-62. doi: 10.1590/S003471672009000300020.

22.Silva RFJ, Pighinelli L. Application of chitosan and buriti oil (Mauritia Flexuosa L.) in skin wound healing. Biotechnol Bioeng. 2017;3(1). doi: 10.15406/ jabb.2017.03.00056.

23.Jaiswal SR, Sontakke SD. Experimental evaluation of analgesic and antiinflammatory activity of simvastatin and atorvastatin. Indian J Pharmacol. 2012;44(4):475-9. doi: 10.4103/02537613.99311.

24.Altman $R$, Bosch $B$, Brune $K$, Patrignani $P$, Young C. Advances in NSAID development: evolution of diclofenac products using pharmaceutical technology. Drugs. 2015 May;75(8):859-77. doi: 10.1007/s40265015-0392-z.

25.Soares CC, Marques TM, Rigolin GG, Neis E, Friaça AMV, Silva AS, Barreto GS, Lopes L. Atividade analgésica do extrato da Pectis jangadensis (S. Moore). Braz J Pharmacog. 2009;19(1):77-81. doi: 10.1590/S0102$695 \times 2009000100016$.

26. Romero ABR, Martins MCC, Nunes PHM, Ferreira NRT, Brito AKS, Cunha PFM, Lima $A$, Assis RC, Araújo EM. In vitro and in vivo antioxidant activity of Buriti fruit (Mauritia flexuosa L.f.). Nutr Hosp. 2015;32(5):215361. doi: 10.3305/nh.2015.32.5.9603.

\section{Correspondence:}

Marília Ursulino Barbosa

Rua Piauí, 917

64003-240 Teresina - PI Brasil

mariliaursulino@hotmail.com

Received: July 27, 2017

Review: Sept 28, 2017

Accepted: Oct 30, 2017
Conflict of interest: none

Financial source: none
${ }^{1}$ Research performed at Laboratory of Physiology, Faculdade Integral Diferencial (FACID| DeVry), Teresina-PI, Brazil. 